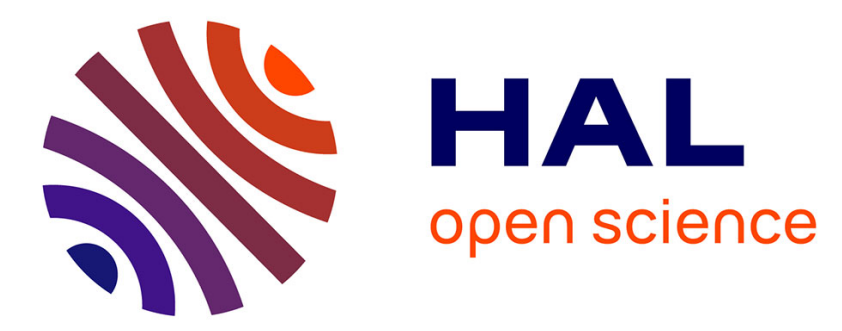

\title{
Controlled degradation of polyisoprene and polybutadiene: A comparative study of two methods
}

Pierre Berto, Stéphane Grelier, Frédéric Peruch

\section{To cite this version:}

Pierre Berto, Stéphane Grelier, Frédéric Peruch. Controlled degradation of polyisoprene and polybutadiene: A comparative study of two methods. Polymer Degradation and Stability, 2018, 154, pp.295 - 303. 10.1016/j.polymdegradstab.2018.06.019 . hal-01870938

\section{HAL Id: hal-01870938 \\ https://hal.science/hal-01870938}

Submitted on 24 Sep 2020

HAL is a multi-disciplinary open access archive for the deposit and dissemination of scientific research documents, whether they are published or not. The documents may come from teaching and research institutions in France or abroad, or from public or private research centers.
L'archive ouverte pluridisciplinaire HAL, est destinée au dépôt et à la diffusion de documents scientifiques de niveau recherche, publiés ou non, émanant des établissements d'enseignement et de recherche français ou étrangers, des laboratoires publics ou privés. 


\title{
Controlled degradation of polyisoprene and polybutadiene: a comparative study of two methods
}

Pierre Berto, Stéphane Grelier, Frédéric Peruch*

Univ. Bordeaux, CNRS, Bordeaux INP/ENSCBP

Laboratoire de Chimie des Polymères Organiques, UMR 5629, 16 avenue Pey-Berland, F33607 Pessac Cedex, France

*E-mail: peruch@enscbp.fr

\section{Keywords:}

Polybutadiene, Polyisoprene, controlled degradation, epoxidation, periodic acid, mCPBA

\begin{abstract}
:
Low molar mass carbonyl telechelic cis,1-4 polyisoprene (CTPI) and aldehyde telechelic cis,14 polybutadiene (ATPB) were easily prepared by the controlled degradation of high molar mass 1,4-cis polyisoprene (PI) and 1,4-cis polybutadiene (PB) in a molar mass range of $5000-$ 80000 g.mol ${ }^{-1}$. Two methods are compared: the direct one using only the periodic acid $\left(\mathrm{H}_{5} \mathrm{IO}_{6}\right)$ to randomly cleave the chain and a second one where the chain are first epoxidized before being cleaved by the periodic acid. In both cases, a control of the final chain length was observed with nevertheless a better control of the final chain length, dispersity and chain-ends using the 2steps procedure. Importance of the washing step in order to avoid side reactions on the carbonyl chain-ends is also discussed.
\end{abstract}




\section{Introduction}

A large variety of chain-cleavage reactions to produce low molar mass polybutadiene or polyisoprene with various chain-ends have been developed because of the use of these latter in many applications such as membranes, adhesives, coating, sealant, propellant or as a building block for ABA triblock copolymers or reversible cross-linked networks as recently demonstrated [1-9]. Among them, one can cite ozonolysis,[10] biodegradation,[11] photodegradation,[12] ultrasonic irradiation,[13] metathesis [14-16] and oxidative chemical degradation by periodic acid or by scission of partially epoxidized polydiene (EPD) with periodic acid. [17-24] The two last methods give the best results for mass control and dispersity leading to the formation of an aldehyde telechelic polybutadiene (ATPB) and a carbonyl telechelic polyisoprene (CTPI) according to the polydiene used, generally in a molar mass range of 3000-20000 g/mol. However, no report has clearly demonstrated which one is the best oxidative chemical degradation pathway to obtain small carbonyl telechelic polydienes (CTPD). Reyx and Pilard focused their work on natural rubber degradation. [17,20] They demonstrated that it is possible to tune the final chain length of the CTPI by monitoring the ratio between periodic acid and double-bonds of the polydiene. They also showed that it is possible to degrade partially the epoxidized PI (EPI) with periodic acid and that the EPI is more reactive towards periodic acid than PI. Indeed, the epoxidized units are rapidly cleaved to obtain the carbonyl chain end groups. On another hand, Zhou and coll. showed that ATPB can be easily obtained by the chain scission of an epoxidized polybutadiene (EPB), the final chain length being controlled by the epoxidation rate.[18,19] Nevertheless, no study compares directly the two methods. To the best of our knowledge, no study on the direct cleavage of PB with only periodic acid was published.

In this paper, the two main oxidative chemical degradation methods to obtain CTPI and ATPB were compared. PI and PB were either degraded by periodic acid alone or by the method which 
requires a preliminary epoxidation step before cleavage. Results are carefully compared to determine the best method leading to the control of the final chain length, the chain end groups and the chain dispersity. Moreover, we report for the first time the importance of the purification step following the polymer degradation in order to avoid side reactions which deteriorate the aldehyde chain end function.

\section{Experimental section}

\section{Materials and methods}

Cis-1,4-polybutadiene (98\% cis-1,4, $\left.M_{n}=150 \mathrm{~kg} \cdot \mathrm{mol}^{-1}, Ð=2.8\right)$ and cis-1,4-polyisoprene (98\% cis-1,4, $M_{n}=635 \mathrm{~kg} \cdot \mathrm{mol}^{-1}, Ð=2.1$ ) were purchased from Scientific Polymer Products, Inc. 3Chloroperoxybenzoic acid (mCPBA, 70-75\%, Acros), periodic acid $\left(\mathrm{H}_{5} \mathrm{IO}_{6}, \geq 99 \%\right.$, Aldrich) were used without further purification. Tetrahydrofuran (THF) and dichloromethane (DCM), methanol and diethyl ether (reagent grade, Aldrich) were used as received.

Liquid-state ${ }^{1} \mathrm{H}$ and ${ }^{13} \mathrm{C}$ NMR spectra were recorded at $298 \mathrm{~K}$ on a Bruker Avance 400 spectrometer operating at $400 \mathrm{MHz}$ and $100 \mathrm{MHz}$ respectively in appropriate deuterated solvents. Molar masses were determined by size exclusion chromatography (SEC) using tetrahydrofuran (THF) as the eluent (THF with $250 \mathrm{ppm}$ of Butylated hydroxytoluene as inhibitor, Aldrich) at $40^{\circ} \mathrm{C}$. The SEC line is equipped with a Waters pump, a Waters RI detector and a Wyatt Light Scattering detector. The separation is achieved on three Tosoh TSK gel columns $(300 \times 7.8 \mathrm{~mm})$ G5000 HXL, G6000 HXL and a Multipore HXL with an exclusion limits from 500 to $40000000 \mathrm{~g} / \mathrm{mol}$, at flow rate of $1 \mathrm{~mL} / \mathrm{min}$. The injected volume is $100 \mu \mathrm{L}$. Columns' temperature was held at $40{ }^{\circ} \mathrm{C}$. Molar masses were evaluated with polyisoprene standards calibration. Data were processed with Astra software from Wyatt.

Polymers synthesis 


\section{Carbonyl telechelic PI (CTPI) preparation via direct oxidative degradation of PI with}

H5IO6: Example of degradation with a molar ratio $\mathbf{R}=[\mathrm{IU}] /\left[\mathrm{H}_{5} \mathrm{IO}_{6}\right]=38$ (with $\mathrm{IU}=$ Isoprene Units). To a solution of high molar mass cis-1,4-polyisoprene (1.10 g, $16.13 \mathrm{mmol}$ IU) solubilized in $39 \mathrm{~mL}$ of THF, a solution of periodic acid $(96.7 \mathrm{mg}, 0.42 \mathrm{mmol})$ dissolved in 10 $\mathrm{mL}$ of THF was added dropwise and stirred during $6 \mathrm{hrs}$ at room temperature. The solvent was then removed under reduced pressure and the crude product was dissolved in diethyl ether before filtration on celite to removed insoluble iodic acid. The filtrate was then concentrated before washing 2 times with saturated solution (30 mL of each) of $\mathrm{Na}_{2} \mathrm{~S}_{2} \mathrm{O}_{3}, \mathrm{NaHCO}_{3}$ and distilled water. Finally, the organic layer was dried $\left(\mathrm{MgSO}_{4}\right)$, filtered on celite and the solvent was evaporated to dryness to obtain CTPI. $\mathrm{M}_{\mathrm{n}(\mathrm{NMR})}=18600 \mathrm{~g} \cdot \mathrm{mol}^{-1}, \mathrm{M}_{\mathrm{n}(\mathrm{SEC})}=18200 \mathrm{~g} \cdot \mathrm{mol}^{-}$ ${ }^{1}, \mathrm{Ð}=1.3$. Yield $=89 \% .{ }^{1} \mathrm{H}$ NMR $\left(400 \mathrm{MHz}, \mathrm{CDCl}_{3}\right):(\delta, \mathrm{ppm}) 9.77\left(\mathrm{t}, 1 \mathrm{H},-\mathrm{CH}_{2}-\mathrm{CHO}\right), 5.12$ (s, nH, $\left.-\mathrm{CH}_{2}-\mathrm{C}\left(\mathrm{CH}_{3}\right)=\mathrm{CH}-\mathrm{CH}_{2}-\right), 2.49\left(\mathrm{t}, 2 \mathrm{H},-\mathrm{CH}_{2}-\mathrm{CHO}\right), 2.44\left(\mathrm{t}, 2 \mathrm{H},-\mathrm{CH}_{2}-\mathrm{CH}_{2}-\mathrm{C}=\mathrm{O}\left(\mathrm{CH}_{3}\right)\right)$, $2.34\left(\mathrm{t}, 2 \mathrm{H},-\mathrm{CH}_{2}-\mathrm{CH}_{2}-\mathrm{CHO}\right), 2.27\left(\mathrm{t}, 2 \mathrm{H},-\mathrm{CH}_{2}-\mathrm{CH}_{2}-\mathrm{C}=\mathrm{O}\left(\mathrm{CH}_{3}\right)\right), 2.12\left(\mathrm{~s}, 3 \mathrm{H},-\mathrm{CH}_{2}-\mathrm{CH}_{2}-\right.$ $\left.\mathrm{C}=\mathrm{O}\left(\mathrm{CH}_{3}\right)\right), 2.04\left(\mathrm{~s}, 4 \mathrm{nH},-\mathrm{CH}_{2}-\mathrm{C}\left(\mathrm{CH}_{3}\right)=\mathrm{CH}-\mathrm{CH}_{2}-\right), 1.68\left(\mathrm{~s}, 3 \mathrm{nH},-\mathrm{CH}_{2}-\mathrm{C}\left(\mathrm{CH}_{3}\right)=\mathrm{CH}-\mathrm{CH}_{2}-\right)$.

\section{Aldehyde telechelic PB (ATPB) preparation via direct oxidative degradation of PB with} H5IO6: Example of degradation with a molar ratio $\mathbf{R}=[\mathrm{BU}] /\left[\mathrm{H}_{5} \mathrm{IO}_{6}\right]=30$ (with $\mathrm{BU}=$ Butadiene Units). To a solution of high molar mass cis-1,4-polybutadiene (1.10 g, $20.44 \mathrm{mmol}$ BU) solubilized in $39 \mathrm{~mL}$ of THF, a solution of periodic acid $(155 \mathrm{mg}, 0.68 \mathrm{mmol})$ dissolved in $10 \mathrm{~mL}$ of THF was added dropwise and stirred during $6 \mathrm{hrs}$ at room temperature. The solvent was then removed under reduced pressure and the crude product was dissolved in diethyl ether before filtration on celite to remove insoluble iodic acid. The filtrate was then concentrated before washing 2 times with saturated solution (30 mL of each) of $\mathrm{Na}_{2} \mathrm{~S}_{2} \mathrm{O}_{3}, \mathrm{NaHCO}_{3}$ and distilled water. Finally, the organic layer was dried $\left(\mathrm{MgSO}_{4}\right)$, filtered on celite and the solvent was evaporated to dryness to obtain ATPB. $\mathrm{M}_{\mathrm{n}(\mathrm{NMR})}=61300 \mathrm{~g} \cdot \mathrm{mol}^{-1}, \mathrm{M}_{\mathrm{n}}(\mathrm{SEC})=28500 \mathrm{~g} \cdot \mathrm{mol}^{-}$ ${ }^{1}, \mathrm{Ð}=8.0$, yield: $87 \% .{ }^{1} \mathrm{H} \mathrm{NMR}\left(400 \mathrm{MHz}, \mathrm{CDCl}_{3}\right):(\delta, \mathrm{ppm}) 9.77\left(\mathrm{t}, 2 \mathrm{H},-\mathrm{CH}_{2}-\mathrm{CHO}\right), 5.38$ 
(m, 2nH, $\left.-\mathrm{CH}_{2}-\mathrm{CH}=\mathrm{CH}-\mathrm{CH}_{2}-\right), 2.49$ (t, 4H, - $\left.\mathrm{CH}_{2}-\mathrm{CH}_{2}-\mathrm{CHO}\right), 2.38$ (t, 4H, - $\mathrm{CH}_{2}-\mathrm{CH}_{2}-\mathrm{CHO}$ ), $2.09\left(\mathrm{~s}, 4 \mathrm{nH},-\mathrm{CH}_{2}-\mathrm{CH}=\mathrm{CH}-\mathrm{CH}_{2}-\right)$.

Epoxidized polyisoprene (EPI) preparation with mCPBA: Example of epoxidation with a theoretical epoxidation rate of $10 \%$. High molar mass cis-1,4-polyisoprene (6.48 g, $95.29 \mathrm{mmol}$ IU) solubilized in $230 \mathrm{~mL}$ of THF was epoxidized by a dropwise addition at $0^{\circ} \mathrm{C}$ of a mCPBA solution $(9.53 \mathrm{mmol}$ in $10 \mathrm{ml} \mathrm{THF})$. After $2 \mathrm{hrs}$ of reaction at room temperature the solution was concentrated before being purified 3 times by precipitation/dissolution in methanol/DCM and the solvent was evaporated to dryness to obtain EPI. The epoxy units contents was determined by ${ }^{1} \mathrm{H}$ NMR (in \%), yield: $91 \% .{ }^{1} \mathrm{H}$ NMR (400 MHz, $\left.\mathrm{CDCl}_{3}\right) \delta 5.12$ (s, n-mH, $\left.\mathrm{CH}_{2}-\mathrm{C}\left(\mathrm{CH}_{3}\right)=\mathrm{CH}-\mathrm{CH}_{2}-\right), 2.68\left(\mathrm{t}, \mathrm{mH},-\mathrm{CH}-\right.$ epoxy- $\left.\mathrm{CH}_{3}-\right), 2.04\left(\mathrm{~s}, 4 \mathrm{n}-\mathrm{mH},-\mathrm{CH}_{2}-\mathrm{C}\left(\mathrm{CH}_{3}\right)=\mathrm{CH}-\right.$ $\left.\mathrm{CH}_{2}-\right), 1.68\left(\mathrm{~s}, 3 \mathrm{n}-\mathrm{mH},-\mathrm{CH}_{2}-\mathrm{C}\left(\mathrm{CH}_{3}\right)=\mathrm{CH}-\mathrm{CH}_{2}-\right), 1.28\left(\mathrm{~s}, 3 \mathrm{mH},-\mathrm{CH}-\mathrm{epoxy}-\mathrm{CH}_{3^{-}}\right)$.

Epoxidized polybutadiene (EPB) preparation with mCPBA: Example of epoxidation with a theoretical epoxidation rate of $15 \%$. High molar mass cis-1,4-polybutadiene (1.02 g, 18.88 mmol BU) solubilized in $35 \mathrm{~mL}$ of THF was epoxidized by a dropwise addition at $0^{\circ} \mathrm{C}$ of a mCPBA solution $(2.83 \mathrm{mmol}$ in $10 \mathrm{~mL}$ THF). After $2 \mathrm{hrs}$ of reaction at room temperature the solution was concentrated before being purified 3 times by precipitation/dissolution in methanol/DCM and the solvent was evaporated to dryness to obtain EPB. The epoxy units contents was determined by ${ }^{1} \mathrm{H}$ NMR (in \%), yield: $90 \% .{ }^{1} \mathrm{H}$ NMR (400 MHz, $\left.\mathrm{CDCl}_{3}\right) \delta 5.38$ (m, 2n-mH, - $\left.\mathrm{CH}_{2}-\mathrm{CH}=\mathrm{CH}-\mathrm{CH}_{2}-\right), 2.92(\mathrm{t}, 2 \mathrm{mH},-\mathrm{CH}$-epoxy- $\mathrm{CH}-), 2.08$ (s, 4n-mH, - $\mathrm{CH}_{2^{-}}$ $\left.\mathrm{CH}=\mathrm{CH}-\mathrm{CH}_{2-}\right)$.

One-pot Carbonyl telechelic PI (CTPI) preparation via epoxidation (mCPBA) and

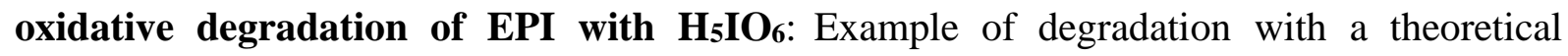
epoxidation rate of $0.54 \%$. High molar mass cis-1,4-polyisoprene (3.87 g, $56.9 \mathrm{mmol}$ IU) solubilized in $135 \mathrm{~mL}$ of THF was first epoxidized by a dropwise addition at $0^{\circ} \mathrm{C}$ of a mCPBA solution $(0.31 \mathrm{mmol}$ in $10 \mathrm{~mL}$ THF). After $2 \mathrm{hrs}$ at room temperature, periodic acid (1.05 eq. 
compared to mCPBA, $0.32 \mathrm{mmol}$ ) dissolved in $10 \mathrm{~mL}$ of THF were added dropwise and stirred during 2 hrs at room temperature The solvent was then removed under reduced pressure and the crude product was dissolved in diethyl ether before filtration on celite to remove insoluble iodic acid. The filtrate was then concentrated before washing 2 times with saturated solution (30 mL of each) of $\mathrm{Na}_{2} \mathrm{~S}_{2} \mathrm{O}_{3}, \mathrm{NaHCO}_{3}$ and distilled water. Finally, the organic layer was dried $\left(\mathrm{MgSO}_{4}\right)$, filtered on celite and the solvent was evaporated to dryness to obtain CTPI. $\mathrm{M}_{\mathrm{n}}$ (NMR) $=23000 \mathrm{~g} \cdot \mathrm{mol}^{-1}, \mathrm{M}_{\mathrm{n}(\mathrm{SEC})}=28500 \mathrm{~g} \cdot \mathrm{mol}^{-1}, \mathrm{Ð}=1.5$. Yield $=91 \% .{ }^{1} \mathrm{H} \mathrm{NMR}\left(400 \mathrm{MHz}, \mathrm{CDCl}_{3}\right)$ : $(\delta, \mathrm{ppm}) 9.77\left(\mathrm{t}, 1 \mathrm{H},-\mathrm{CH}_{2}-\mathrm{CHO}\right), 5.12\left(\mathrm{~s}, \mathrm{nH},-\mathrm{CH}_{2}-\mathrm{C}\left(\mathrm{CH}_{3}\right)=\mathrm{CH}-\mathrm{CH}_{2}-\right), 2.49\left(\mathrm{t}, 2 \mathrm{H},-\mathrm{CH}_{2}-\right.$ $\mathrm{CHO}), 2.44\left(\mathrm{t}, 2 \mathrm{H},-\mathrm{CH}_{2}-\mathrm{CH}_{2}-\mathrm{C}=\mathrm{O}\left(\mathrm{CH}_{3}\right)\right), 2.34\left(\mathrm{t}, 2 \mathrm{H},-\mathrm{CH}_{2}-\mathrm{CH}_{2}-\mathrm{CHO}\right), 2.27\left(\mathrm{t}, 2 \mathrm{H},-\mathrm{CH}_{2}-\right.$ $\left.\mathrm{CH}_{2}-\mathrm{C}=\mathrm{O}\left(\mathrm{CH}_{3}\right)\right), 2.12\left(\mathrm{~s}, 3 \mathrm{H},-\mathrm{CH}_{2}-\mathrm{CH}_{2}-\mathrm{C}=\mathrm{O}\left(\mathrm{CH}_{3}\right)\right), 2.04\left(\mathrm{~s}, 4 \mathrm{nH},-\mathrm{CH}_{2}-\mathrm{C}\left(\mathrm{CH}_{3}\right)=\mathrm{CH}-\mathrm{CH}_{2}-\right)$, $1.68\left(\mathrm{~s}, 3 \mathrm{nH},-\mathrm{CH}_{2}-\mathrm{C}\left(\mathrm{CH}_{3}\right)=\mathrm{CH}-\mathrm{CH}_{2}-\right)$.

One-pot Aldehyde telechelic PB (ATPB) preparation via epoxidation (mCPBA) and oxidative degradation of EPB with $\mathrm{H}_{5}$ IO $_{6}$ : Example of degradation with a theoretical epoxidation rate of $0.91 \%$. High molar mass cis-1,4-polybutadiene (3.76 g, 69.6 mmol BU) solubilized in $130 \mathrm{~mL}$ of THF was first epoxidized by a dropwise addition at $0^{\circ} \mathrm{C}$ of a mCPBA solution (0.63 mmol in $10 \mathrm{~mL}$ THF). After $2 \mathrm{hrs}$ at room temperature, periodic acid (1.05 eq. compared to mCPBA, $0.67 \mathrm{mmol}$ ) dissolved in $10 \mathrm{~mL}$ of THF were added dropwise and stirred during $2 \mathrm{hrs}$ at room temperature. The solvent was then removed under reduced pressure and the crude product was dissolved in diethyl ether before filtration on celite to remove insoluble iodic acid. The filtrate was then concentrated before washing 2 times with saturated solution (30 mL of each) of $\mathrm{Na}_{2} \mathrm{~S}_{2} \mathrm{O}_{3}, \mathrm{NaHCO}_{3}$ and distilled water. Finally, the organic layer was dried $\left(\mathrm{MgSO}_{4}\right)$, filtered on celite and the solvent was evaporated to dryness to obtain CTPB. $\mathrm{M}_{\mathrm{n}}$ (NMR) $=13300 \mathrm{~g} \cdot \mathrm{mol}^{-1}, \mathrm{M}_{\mathrm{n}(\mathrm{SEC})}=15500 \mathrm{~g} \cdot \mathrm{mol}^{-1}, \mathrm{D}=1.7$, yield: $88 \% .{ }^{1} \mathrm{H} \mathrm{NMR}\left(400 \mathrm{MHz}, \mathrm{CDCl}_{3}\right)$ : $(\delta, \mathrm{ppm}) 9.77\left(\mathrm{t}, 2 \mathrm{H},-\mathrm{CH}_{2}-\mathrm{CHO}\right), 5.38\left(\mathrm{~m}, 2 \mathrm{nH},-\mathrm{CH}_{2}-\mathrm{CH}=\mathrm{CH}-\mathrm{CH}_{2}-\right), 2.49\left(\mathrm{t}, 4 \mathrm{H},-\mathrm{CH}_{2}-\mathrm{CH}_{2}-\right.$ CHO), 2.38 (t, 4H, - $\left.\mathrm{CH}_{2}-\mathrm{CH}_{2}-\mathrm{CHO}\right), 2.09$ (s, 4nH, $\left.-\mathrm{CH}_{2}-\mathrm{CH}=\mathrm{CH}-\mathrm{CH}_{2}-\right)$ 


\section{Results and discussions}

Importance of the purification step in order to obtain well defined carbonyl telechelic dienes

Degradation of the EPI and EPB with periodic acid was already known. Reyx, who developed the degradation of EPD by periodic acid, has purified the products by a simple precipitation in methanol.[25,17] Pilard and coll. used a different strategy by dissolving the crude and dried CTPI product in dichloromethane before washing it with a concentrated aqueous solution of $\mathrm{NaHCO}_{3}, \mathrm{Na}_{2} \mathrm{~S}_{2} \mathrm{O}_{3}$ and water and finally drying on $\mathrm{MgSO}_{4}$.[20,26] More recently, they used a simple precipitation of the ATPB reaction mixture into ethanol after a filtration step on Celite to remove the iodic acid.[18,19]

In this study, the direct precipitation in methanol was first used for its simplicity and quickness. Nevertheless, after the purification of the degraded PI and PB, it was observed a huge difference between the calculated $M_{n N M R}$ and $M_{n \text { SEC. }}$ Indeed, in all of cases the $M_{n N M R}$ calculated thanks to the aldehyde function was always far higher than the $M_{n} S E C$. One explanation could have been the non-reaction of some epoxy units, but the epoxy signal on the ${ }^{1} \mathrm{H}$ NMR spectrum had totally disappeared. Another explanation could be that secondary reactions could occur onto the aldehyde functions. Indeed, if for any reason the aldehyde groups are modified, the $M_{n N M R}$ will be automatically increased as this signal serves to calculate $\mathbf{M}_{n N M R}$. Acetal formation between the aldehyde and the methanol under our conditions could be an issue (Scheme 1).
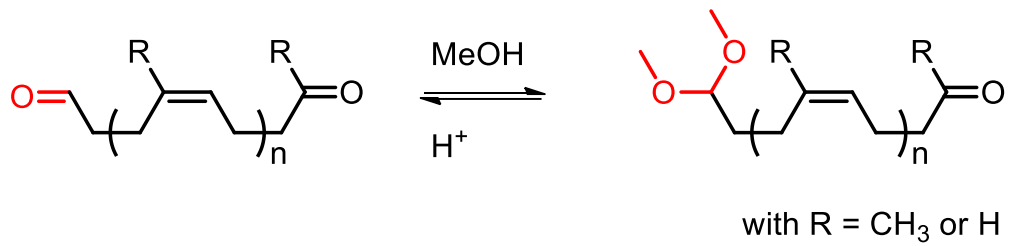

Scheme 1: Acetal formation in the presence of methanol and acid at CTPD chain-end. 
For example, an ATPB was prepared by the scission of an EPB epoxidized at $0.37 \%$ with periodic acid. After purification by precipitation in methanol, SEC analyses reveal a molar mass of 37900 g.mol ${ }^{-1}$ whereas the $M_{n}$ NMR was equal to 64840 g.mol ${ }^{-1}$. Therefore, the ${ }^{1} \mathrm{H}$ NMR analysis show the appearance of two news signals: a singlet at $3.32 \mathrm{ppm}$ and a triplet at 4.37 ppm (signals 7 and $\mathbf{6}$ respectively, Figure 1). Integration of these protons signals were in good agreement with the hypothesis of the acetal formation. In each case, a ratio of 1:6 for the signals 6 and 7 respectively was observed (Figure 1). Moreover, this side reaction has already been observed on small molecules (Figure 2).[27]

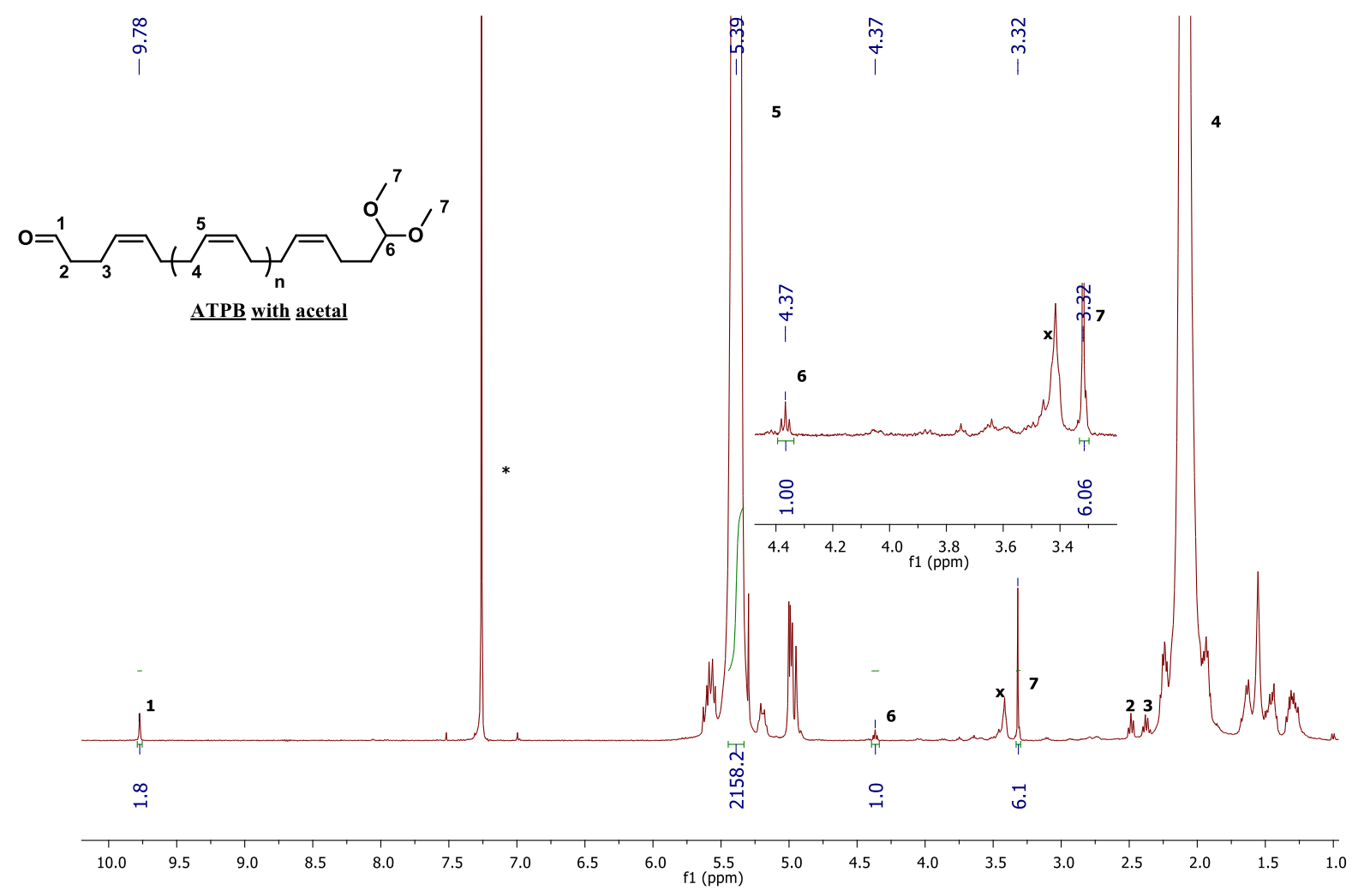

Figure 1: ${ }^{1} \mathrm{H}$ NMR spectrum of a ATPB with partial acetal chain-end formation $\left({ }^{*} \mathrm{CDCl}_{3}\right)$

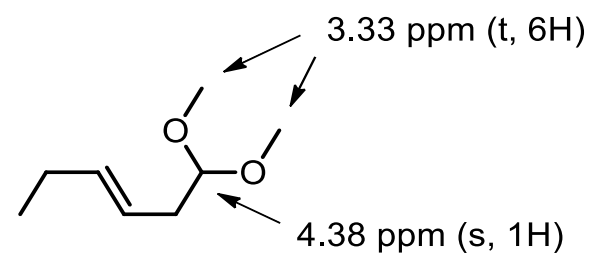

Figure 2: Structure and ${ }^{1} \mathrm{H}$ NMR shift of a small molecule similar to the acetal chain end of a PI or PB. [27] 
Finally, by calculating the $M_{n N M R}$ with the formula $M_{n N M R}=\left[\frac{I(5,38)}{I(9.77)+I(4.37)} \times 54\right]+100$ taking into account the aldehyde and the acetal groups, the $M_{n N M R}$ is equal to $41700 \mathrm{~g} \cdot \mathrm{mol}^{-1}$, which is in good agreement with the $M_{n}$ SEC $\left(37900 \mathrm{~g} \cdot \mathrm{mol}^{-1}\right)$. This confirms the hypothesis of the acetal chain end formation. Deacetalisation reaction was performed under acidic conditions and all the aldehyde functions were retrieved. The purification method was thus modified as described in the experimental part to obtain the CTPD without acetal chain-end.

\section{CTPI preparation by oxidative degradation of the PI with periodic acid}

The first investigated route to obtain carbonyl telechelic polydienes (CTPD) was the direct oxidative degradation of the polymer by the $\mathrm{H}_{5} \mathrm{IO}_{6}$ (Scheme 2, pathway 1).

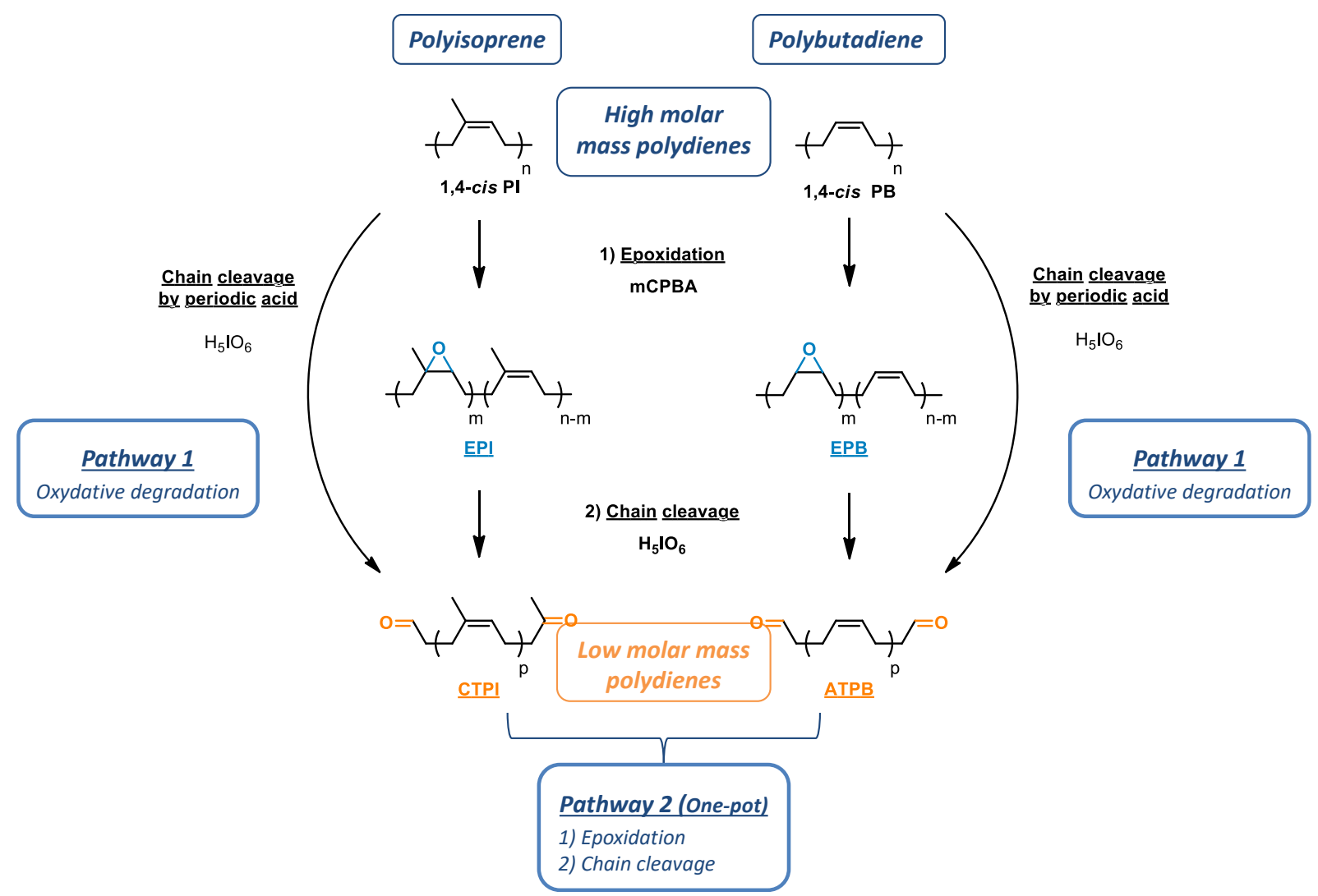

Scheme 2 : Oxidative routes to obtain small carbonyl telechelic polydienes (CTPD). Pathway 1: chain cleavage by periodic acid, Pathway 2 : Chain cleavage of epoxidized polydienes (EPD). 
This reaction, involving two equivalents of $\mathrm{H}_{5} \mathrm{IO}_{6}$ to cleave a double bond is described as a twosteps mechanism:[17] a first molecule of $\mathrm{H}_{5} \mathrm{IO}_{6}$ reacts with a double bond to lead to an epoxide or a $\alpha$-glycol and a second equivalent of $\mathrm{H}_{5} \mathrm{IO}_{6}$ cleave these bonds in order to obtain the CTPD (Scheme 3). According to the initial polymer (PI or PB), the final CTPD will be different: if the starting material is PI, the chain-ends will be an aldehyde and a ketone (CTPI). But if the degradation concerns PB, the chain-ends will be both an aldehyde (ATPB) as shown in Scheme

3.

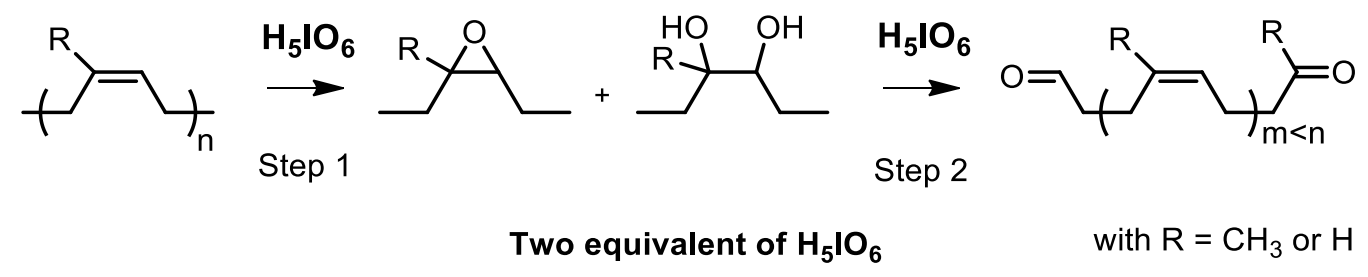

Scheme 3: Two steps reaction of the oxidative degradation of PI and PB under $\mathrm{H}_{5} \mathrm{IO}_{6}$ treatment.

To a high molar mass PI solution $\left(635 \mathrm{~kg}^{\mathrm{mol}} \mathrm{m}^{-1}\right)$ in THF, a solution of periodic acid in THF was added dropwise and stirred for $6 \mathrm{hrs}$ at $25^{\circ} \mathrm{C}$ as described in the literature.[17] ${ }^{1} \mathrm{H}$ NMR analysis of a degraded PI obtained by action of the periodic acid is shown on Erreur ! Source du renvoi introuvable..

The chain length of the final CTPI could be theoretically predicted by monitoring the quantity of periodic acid. To confirm that, a series of degradation was performed by varying the molar ratio $\mathrm{R}=[\mathrm{IU}] /\left[\mathrm{H}_{5} \mathrm{IO}_{6}\right]$ between 5 and 230. The synthesized CTPIs were characterized by SEC and NMR. Results are summarized in Table 1. An increase of the quantity of periodic acid compared to the isoprenic units is associated to a decrease of the final molar mass. In all cases, SEC analyses reveal a narrow dispersity $Đ$ between 1.3 and 1.7 with a decreasing trend for the smaller chains (Table 1, entries 4-8). The comparison of the $M_{n}$ calculated by SEC and NMR shows a growing gap with the chain length increase as for shorter chains; $M_{n}$ SEC is higher than $M_{n}$ NMR whereas it is the opposite for longer chains. This can be attributed to the difficulty to 
evaluate the $M_{n}$ NMR for high molar masses. This difference could also be due to the functionality of the polymer. Indeed, to calculate the NMR molar mass it was assumed a functionality of 2, but the theoretical functionality that can be calculated taking into account the degradation process (see ESI for details) is always below 2. In our case, starting from a PI precursor of $635000 \mathrm{~g} / \mathrm{mol}$, functionality varied from 1.79 to 1.98 with the lower the targeted molar mass, the higher the functionality. Moreover, measured molar masses are always much higher than the theoretical ones. This could be due to a low efficiency of periodic acid, meaning that more than 2 molecules of periodic acid are needed to cleave a double bond.

Table 1 : Oxidative cleavage of PI by periodic acid: influence of $\mathrm{R}=[\mathrm{IU}] /\left[\mathrm{H}_{5} \mathrm{IO}_{6}\right]$.

\begin{tabular}{|c|c|c|c|c|c|c|}
\hline entry & $\begin{array}{c}\mathrm{R} \\
\mathrm{n}[\mathrm{IU}] / \mathrm{n}[\mathrm{H} 5 \mathrm{IO} 6]\end{array}$ & $\begin{array}{c}M_{n \mathrm{th}^{\mathrm{a}}} \\
\left(\mathrm{g} \cdot \mathrm{mol}^{-1}\right)\end{array}$ & $\begin{array}{l}\left.M_{n} \mathrm{NMR}^{\mathrm{b}}\right) \\
\left(\mathrm{g} \cdot \mathrm{mol}^{-1}\right)\end{array}$ & $\begin{array}{l}M_{n \mathrm{SEC}^{\mathrm{c}}} \\
\left(\mathrm{g} \cdot \mathrm{mol}^{-1}\right)\end{array}$ & $\bigoplus^{\mathrm{d})}$ & $\begin{array}{c}\text { Calculated } \\
\text { Functionality }\end{array}$ \\
\hline 1 & 230 & 31280 & 85000 & 66000 & 1.7 & 1.79 \\
\hline 2 & 143 & 19450 & 52900 & 44800 & 1.5 & 1.86 \\
\hline 3 & 120 & 16320 & 34200 & 29830 & 1.6 & 1.91 \\
\hline 4 & 70 & 9520 & 29900 & 24000 & 1.3 & 1.92 \\
\hline 5 & 38 & 5170 & 18600 & 18200 & 1.3 & 1.94 \\
\hline 6 & 25 & 3400 & 10880 & 14300 & 1.4 & 1.95 \\
\hline 7 & 10 & 1360 & 4900 & 9900 & 1.4 & 1.97 \\
\hline 8 & 5 & 680 & 4650 & 7900 & 1.4 & 1.98 \\
\hline
\end{tabular}

Conditions: $[\mathrm{PI}]=28.5 \mathrm{~g} / \mathrm{L}, \mathrm{T}=25^{\circ} \mathrm{C}$, reaction time $=6 \mathrm{hrs}$

a) theoretical molar mass calculated according to the following equation : $M_{n}$ th $=\mathrm{R} \times 2 \times 68$

b) molar mass evaluated by ${ }^{1} \mathrm{H}$ NMR according to the following equation: $M_{n N M R}=$ $\left[\frac{I(5.12)}{I(9.77)} \times 68\right]+100$

${ }^{\text {c) }}$ molar mass measured by Size Exclusion Chromatography in THF vs PI standards 
d) dispersity measured by Size Exclusion Chromatography

e) theoretical functionality calculated according to the equation: $F=2 *\left(1-\frac{M n S E C}{635000}\right)$

Plots of the calculated $\mathrm{M}_{n}$ by SEC or NMR $v s$ R are shown on Figure 3 and reveal a linear relationship between $\mathrm{M}_{n}$ and $\mathrm{R}$, which allows to target the desired chain length by monitoring R. These results indicate that well-defined CTPI can be obtained in the range of $3000-80000$ g.mol ${ }^{-1}$ with a low dispersity by using this degradation method.

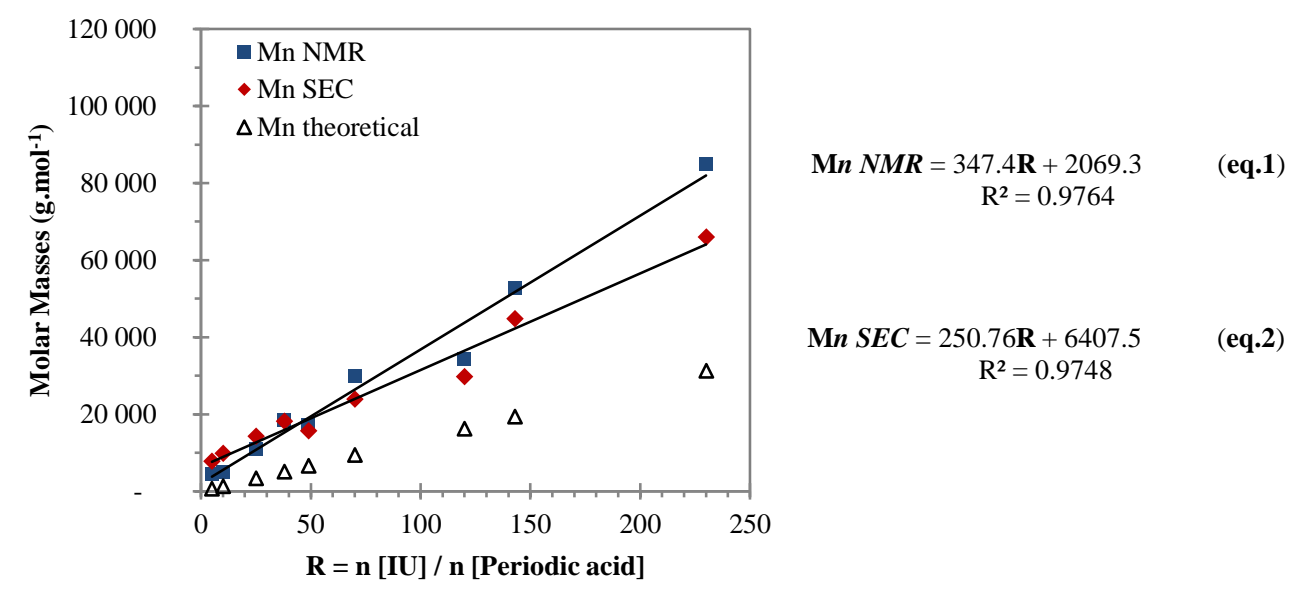

Figure 3: Evolution of $\mathrm{M}_{n}$ vs $\mathrm{R}=[\mathrm{IU}] /\left[\mathrm{H}_{5} \mathrm{IO}_{6}\right]$

\section{ATPB preparation by oxidative degradation of the PB with periodic acid}

A similar study was performed on the polybutadiene polymer. A high molar mass PB (200 $\mathrm{kg} \cdot \mathrm{mol}^{-1}$ ) was degraded by periodic acid in the same conditions as PI in order to obtain small ATPB. A typical ${ }^{1} \mathrm{H}$ NMR analysis of the ATPB is shown on Erreur ! Source du renvoi introuvable. and allows to calculate $M_{n}$ NMR. As demonstrated previously, it is theoretically possible to predict the final chain length by monitoring $\mathrm{R}^{\prime}=[\mathrm{BU}] /\left[\mathrm{H}_{5} \mathrm{IO}_{6}\right]$. Analysis of the obtained polymer is summarized on Table 2, plot of $\mathrm{M}_{n}$ as a function of $\mathrm{R}^{\prime}$ is also represented on Figure 4. 
Compared to the values previously obtained with PI, degradation of PB with periodic acid alone seems less adapted. First, SEC analysis reveals a higher dispersity from 1.8 to 2.6 for the longer chain length (entry 9 vs 14, Table 2). Production of small chains seems to be difficult. Indeed, even for the higher quantities of periodic acid (entry 13 and 14, Table 2), the final molar mass stay relatively high.

Table 2: Oxidative cleavage of the PB by periodic acid: influence of $\mathrm{R}=[\mathrm{BU}] /\left[\mathrm{H}_{5} \mathrm{IO}_{6}\right]$.

\begin{tabular}{|c|c|c|c|c|c|c|}
\hline entry & $\begin{array}{c}\mathrm{R} \\
\mathrm{n}[\mathrm{BU}] / \mathrm{n}[\mathrm{H} 5 \mathrm{IO} 6]\end{array}$ & $\begin{array}{c}M_{n \mathrm{th}^{\mathrm{a}}} \\
\left(\mathrm{g} \cdot \mathrm{mol}^{-1}\right)\end{array}$ & $\begin{array}{l}\left.M_{n \mathrm{NMR}^{\mathrm{b}}}{ }^{-1}\right) \\
\left(\mathrm{g} \cdot \mathrm{mol}^{-1}\right)\end{array}$ & $\begin{array}{l}\left.M_{n \mathrm{SEC}^{\mathrm{c}}}\right) \\
\left(\mathrm{g} \cdot \mathrm{mol}^{-1}\right)\end{array}$ & $\bigoplus^{\mathrm{d})}$ & $\begin{array}{c}\text { Calculated } \\
\left.\text { Functionality }{ }^{\mathrm{e}}\right)\end{array}$ \\
\hline 9 & 93 & 10040 & 106900 & 79000 & 2.6 & 0.95 \\
\hline 10 & 70 & 7560 & 49500 & 57000 & 2.2 & 1.24 \\
\hline 11 & 45 & 4860 & 68000 & 40400 & 2.2 & 1.46 \\
\hline 12 & 30 & 3240 & 61300 & 28500 & 2.0 & 1.62 \\
\hline 13 & 10 & 1080 & 49000 & 25000 & 2.0 & 1.67 \\
\hline 14 & 5 & 540 & 19000 & 37000 & 1.8 & 1.51 \\
\hline
\end{tabular}

Conditions : $[\mathrm{PB}]=28.5 \mathrm{~g} / \mathrm{L}, \mathrm{T}^{\circ}=25^{\circ} \mathrm{C}$, reaction time $6 \mathrm{hrs}$

a) theoretical molar mass calculated according to the following equation: $M_{n t h}=\mathrm{R} \times 2 \times 54$

b) molar mass evaluated by ${ }^{1} \mathrm{H}$ NMR according to the following equation: $M_{n N M R}=$ $\left[\frac{I(5.38)}{I(9.77)} \times 54\right]+100$

${ }^{c}$ molar mass measured by Size Exclusion Chromatography in THF vs PI standards

d) dispersity measured by Size Exclusion Chromatography

e) theoretical functionality calculated according to the equation: $F=2 *\left(1-\frac{M n S E C}{150000}\right)$

Moreover, in contrast to PI, the comparison of $M_{n N M R}$ with $M_{n S E C}$ of the PB shows considerable differences. For example $M_{n N M R}$ is equal to $61300 \mathrm{~g} \cdot \mathrm{mol}^{-1}$ whereas $M_{n}$ SEC is $28500 \mathrm{~g} \cdot \mathrm{mol}^{-1}$ 
when $\mathrm{R}^{\prime}=30$ (entry 12, Table 2). More importantly, equations of the linear regression of ATPB (eq.3 and 4, Figure 4) obtained by plotting $\mathrm{M}_{n}$ as a function of R' clearly show very low coefficient ( 0.637 and 0.788 for $M_{n} N M R$ and $M_{n}$ SEC respectively). This confirms that the degradation method to obtain well-defined and small ATPB is not fully controlled. Moreover, in this case, the calculated functionality is also quite low going from 0.95 to 1.67 , which is far below the expected functionality of 2 and can also explain the huge difference observed between $M_{n} N M R$ and $M_{n} S E C$.

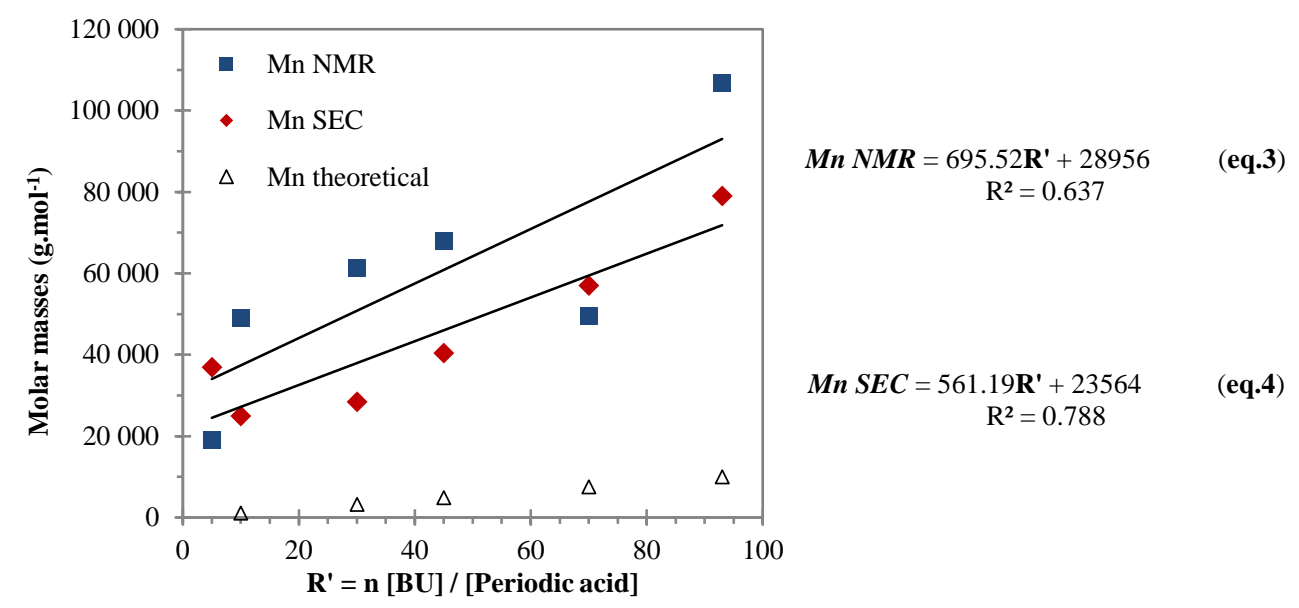

Figure 4: Evolution of $\mathrm{M}_{n} v s$ of $\mathrm{R}^{\prime}=[\mathrm{BU}] /\left[\mathrm{H}_{5} \mathrm{IO}_{6}\right]$

\section{Degradation of PI and PB by epoxidation followed by oxidative cleavage}

The other classical approach to obtain small CTPD is to epoxidize first the polydiene backbone with a peracid, followed by the cleavage of the oxirane groups with the periodic acid. The commonly used oxidizing agents are generally $\mathrm{HCOOH} / \mathrm{H}_{2} \mathrm{O}_{2}$ or the meta-chloroperoxybenzoic acid (mCPBA). The last one was chosen for this study because of its stability and ease of use. Mechanism of the epoxidation followed by the degradation is represented on Scheme 4. 


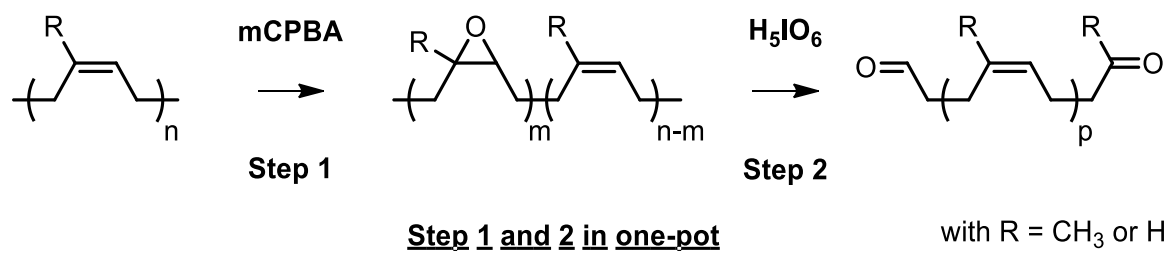

Scheme 4: Two steps mechanism of the one pot oxidative degradation of PI and PB.

\section{Epoxidation control of PI and PB}

In order to study the degradation of the epoxidized dienes with periodic acid, efficiency of the epoxidation with mCPBA was first studied. A series of EPI and EPB with an epoxy content varying from 5 to $40 \%$ were synthesized in the conditions described in the literature.[18] A typical ${ }^{1} \mathrm{H}$ NMR of EPI and EPB are shown on Erreur ! Source du renvoi introuvable. . The epoxidation rate (Epoxy $\exp _{\text {p }} \%$ ) was calculated by using the signal of the epoxidized units at 2.69 ppm and 2.79 ppm for the EPI and EPB respectively. Results of the epoxidation experiments are summarized in Table 3.

Table 3: Epoxidation rate (\%) of PI and PB obtained after mCPBA treatment.

\begin{tabular}{|c|c|c|c|c|c|}
\hline \multicolumn{3}{|c|}{ Polyisoprene } & \multicolumn{3}{|c|}{ Polybutadiene } \\
\hline entry & Epoxy $_{\text {theo }} \%$ & $\mathbf{E p o x y}_{\text {exp }} \%^{\text {a) }}$ & entry & Epoxy $_{\text {theo }} \%$ & $\mathbf{E p o x y}_{\text {exp }} \%$ b) \\
\hline 15 & 5.0 & 5.1 & 21 & 5.0 & 4.8 \\
\hline 16 & 10.0 & 9.9 & 22 & 10.0 & 9.9 \\
\hline 17 & 15.0 & 14.0 & 23 & 15.0 & 14.2 \\
\hline 18 & 20.0 & 19.8 & 24 & 20.0 & 16.5 \\
\hline 19 & 25.0 & 24.8 & 25 & 25.0 & 23.1 \\
\hline 20 & 40.0 & 37.5 & 26 & 30.0 & 26.5 \\
\hline
\end{tabular}

Conditions : [Polydiene $]=28.5 \mathrm{~g} / \mathrm{L}, \mathrm{T}^{\circ}=25^{\circ} \mathrm{C}, \overline{\text { reaction time } 2 \mathrm{~h}}$ 
a) The epoxidation rate (Epoxy $\exp _{\%} \%$ ) of the PI was calculated according to the following equation: $\operatorname{Epoxy}_{\exp } \%=\frac{I(2.69)}{I(2.69+5.12)} \times 100$

b) The epoxidation rate $\left(\right.$ Epoxy $\left._{\exp } \%\right)$ of the $\mathrm{PB}$ was calculated according to the following equation: $\operatorname{Epoxy}_{\exp } \%=\frac{I(2.79)}{I(2.79+5.24)} \times 100$

It appears that epoxidation of a double bond is nearly equimolar with mCBPA for both PI and PB. Epoxy exp $_{\%}$ vs Epoxy theo \% for PI and PB are presented on Figure 5a and b, confirming the linear relationship between the amount of mCPBA and the final epoxidation rate. For EPI, the epoxy content increases linearly with a slope of 0.96 confirming the almost equimolarity of the reaction. However, even if the epoxy content of EPB increases also linearly, the slope is only 0.90 . This indicates that in the same conditions as for PI, only $90 \%$ of mCPBA react with the double bond of PB (96\% for PI). This surprising result is difficult to interpret, as the PB double bonds are less hindered than those of PI, it was expected to have a better reactivity. Epoxidation reaction was also performed on 2 other commercial 1,4-cis PB with chain length of 3000 and $40000 \mathrm{~g} / \mathrm{mol}$ and the epoxy content was also lower than the theoretical one. Nevertheless, it was possible to precisely control the epoxy rate of the PI and the PB by controlling the mCPBA amount. 

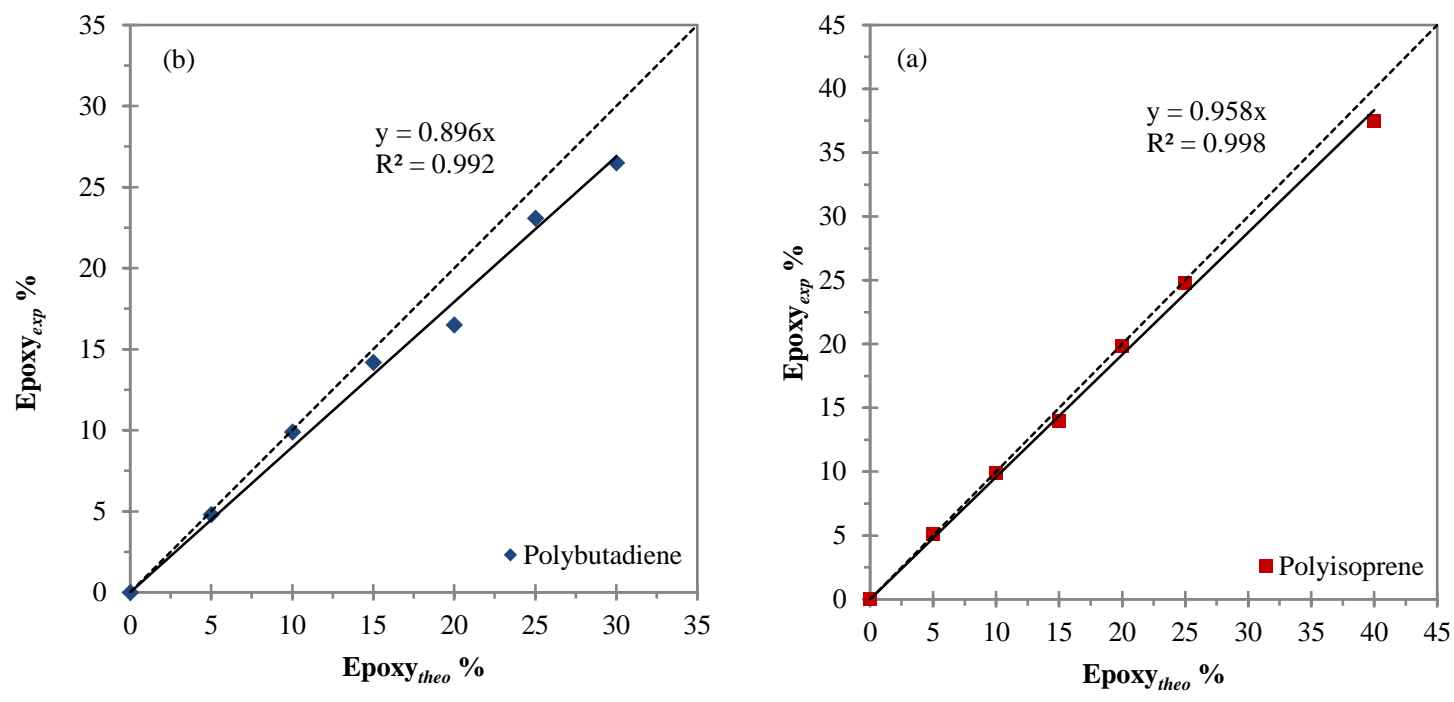

Figure 5: Experimental epoxidation rate vs the theoretical one for the PI (a) and the PB (b).

\section{PI degradation by epoxidation followed by oxidative cleavage}

After having confirmed the linear relationship between the theoretical and experimental epoxidation rate, one-pot degradation of EPI was performed in order to obtain small CTPI. First, epoxidation of PI was performed followed by the direct addition of a solution of periodic acid to the reactive mixture. A molar ratio $\mathrm{H}_{5} \mathrm{IO}_{6} / \mathrm{mCPBA}$ of 1.05 was carefully chosen to avoid the presence of residual epoxidized units. On the contrary, a too high amount of $\mathrm{H}_{5} \mathrm{IO}_{6}$ will lead to additional degradation of the chains by the oxidative cleavage by $\mathrm{H}_{5} \mathrm{IO}_{6}$ alone as shown previously. Results are summarized in Table 4 . Whatever the targeted mass, $M_{n N M R}$ was very close to $M_{n} S E C$ with a low dispersity ranged between 1.5 and 1.3 , even for the highest masses. These results indicate that this method seems to be more precise than the degradation with periodic acid alone, giving well defined CTPI with a lower dispersity and a better control of the carbonyl chain-ends. Indeed, in this case, except for the highest targeted molar mass, the functionality is always higher than 1.9 and very close to 2 for the lowest targeted molar masses. ${ }^{1} \mathrm{H}$ NMR analyses of the CTPI obtained by this way are identical to the one obtained by the direct cleavage with periodic acid (Erreur ! Source du renvoi introuvable.) with the absence of residual epoxy units. 
Table 4: One-pot degradation results for the synthesis of CTPI (EPI cleaved by periodic acid).

\begin{tabular}{|c|c|c|c|c|c|c|}
\hline entry & $\operatorname{Epoxy}_{t h} \%$ & $\begin{array}{l}M_{n \text {th }^{\mathrm{a}}} \\
\left(\mathrm{g} \cdot \mathrm{mol}^{-1}\right)\end{array}$ & $\begin{array}{l}\boldsymbol{M}_{\boldsymbol{n}} \mathrm{NMR}^{\mathrm{b})} \\
\left(\mathrm{g} \cdot \mathrm{mol}^{-1}\right)\end{array}$ & $\begin{array}{l}M_{\left.n \mathrm{SEC}^{\mathrm{c}}\right)} \\
\quad\left(\mathrm{g} \cdot \mathrm{mol}^{-1}\right)\end{array}$ & $\boldsymbol{Ð}^{\mathrm{d})}$ & $\begin{array}{c}\text { Calculated } \\
\text { Functionality }\end{array}$ \\
\hline 27 & 0.26 & 26150 & 52800 & 57000 & 1.5 & 1.82 \\
\hline 28 & 0.35 & 19430 & 41000 & 37000 & 1.5 & 1.88 \\
\hline 29 & 0.39 & 17440 & 37400 & 33500 & 1.5 & 1.89 \\
\hline 30 & 0.54 & 12590 & 23000 & 28500 & 1.5 & 1.91 \\
\hline 31 & 0.74 & 9190 & 20200 & 15100 & 1.5 & 1.95 \\
\hline 32 & 1.06 & 6410 & 14700 & 12400 & 1.4 & 1.96 \\
\hline 33 & 1.17 & 5810 & 12500 & 10200 & 1.4 & 1.97 \\
\hline 34 & 1.30 & 5230 & 9700 & 12000 & 1.3 & 1.96 \\
\hline 35 & 1.60 & 4250 & 9400 & 7100 & 1.5 & 1.98 \\
\hline 36 & 2.10 & 3240 & 4800 & 6400 & 1.5 & 1.98 \\
\hline 37 & 3.20 & 2120 & 3600 & 4800 & 1.3 & 1.98 \\
\hline
\end{tabular}

Conditions : $[\mathrm{PI}]=28.5 \mathrm{~g} / \mathrm{L}, \mathrm{T}^{\circ}=25^{\circ} \mathrm{C}$.

a) theoretical molar mass calculated according to the following equation: $M_{n \text {th }}=\frac{100}{\text { Epoxy th } \%} \times 68$

b) molar mass evaluated by ${ }^{1} \mathrm{H}$ NMR according to the following equation: $M_{n N M R}=$ $\left[\frac{I(5.12)}{I(9.77)} \times 68\right]+100$

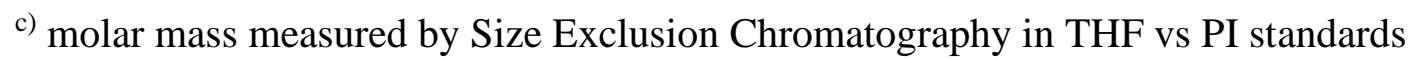

d) dispersity measured by Size Exclusion Chromatography

e) theoretical functionality calculated according to the equation: $F=2 *\left(1-\frac{M n S E C}{635000}\right)$

Plot of $M_{n}$ vs 1/Epoxytheo is represented on Figure 6 and shows a linear relationship between $M_{n N M R}$ or $M_{n S E C}$ and 1/ Epoxy theo (\%). Linear regression equations (eq. 5 and 6, Figure 6) 
confirm the previous observations with a coefficient over 0.98 in the two cases, and the intercept of the regression line under $1000 \mathrm{~g} \cdot \mathrm{mol}^{-1}$. This method seems to be more adapted to get wellcontrolled CTPI in a range $3000-50000$ g. $\mathrm{mol}^{-1}$ with a low dispersity.

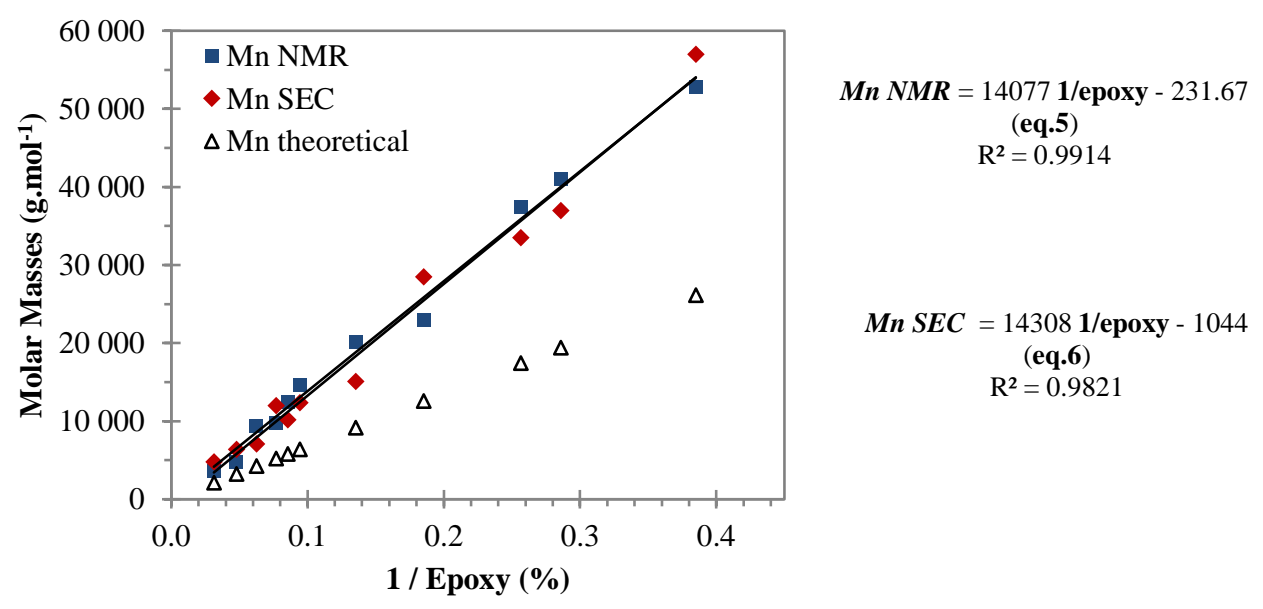

Figure 6: Evolution of $\mathrm{M}_{n}$ vs 1/Epoxy \% of the CTPI obtained by degradation of EPI with $\mathrm{H}_{5} \mathrm{IO}_{6}$.

\section{PB degradation by epoxidation followed by oxidative cleavage}

The protocol implemented for the degradation of the EPB by $\mathrm{H}_{5} \mathrm{IO}_{6}$ is identical to the one used for the EPI. Results are summarized in Table 5. Compared to degradation with periodic acid alone, the degradation of the EPB gives a far better control. The dispersity is close to 1.7 for molar masses ranging from 4000 to $45000 \mathrm{~g} \cdot \mathrm{mol}^{-1}$, while with the direct cleavage, dispersity was comprised between 1.8 and 2.6. Nevertheless, an increases of $Đ$ until 2.6 for the chain under 4000 g.mol ${ }^{-1}$ is observed. As for the EPI degradation, $M_{n N M R}$ is very close to $M_{n} S E C$ independently of the chain length confirming the reliable control of the reaction to obtain ATPB.

Table 5: One pot cleavage of the EPB by periodic acid: influence of the epoxidation rate. 


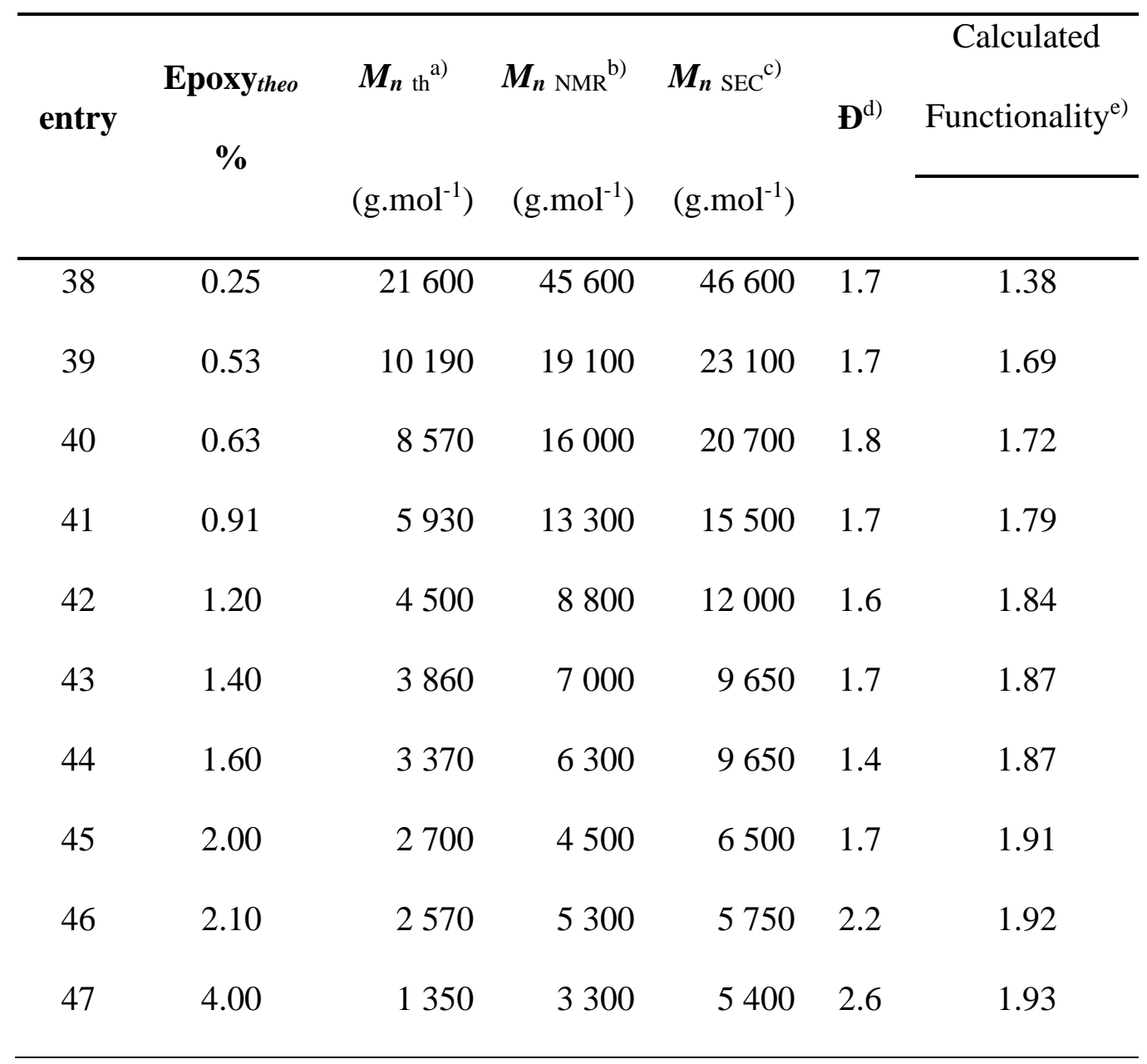

Conditions : $[\mathrm{PB}]=28.5 \mathrm{~g} / \mathrm{L}, \mathrm{T}^{\circ}=25^{\circ} \mathrm{C}$

a) theoretical molar mass calculated according to the following equation: $M_{n \text {th }}=\frac{100}{E p o x y \text { th } \%} \times 54$

b) molar mass evaluated by ${ }^{1} \mathrm{H}$ NMR according to the following equation: $M_{n N M R}=$ $\left[\frac{I(5.38)}{I(9.77)} \times 54\right]+100$

${ }^{c)}$ molar mass measured by Size Exclusion Chromatography in THF vs PI standards

d) dispersity measured by Size Exclusion Chromatography

e) theoretical functionality calculated according to the equation: $F=2 *\left(1-\frac{M n S E C}{150000}\right)$

Nevertheless, the functionality of the degraded polybutadienes is lower than in the case of PI. Indeed, whereas the functionality is higher than 1.9 for degraded PI up to $30000 \mathrm{~g} / \mathrm{mol}$, in the case of PB, a functionality of 1.9 is obtained only for degraded PB below $7000 \mathrm{~g} / \mathrm{mol}$. This difference is only due to the molar mass of the starting polymer which is lower in the case of 
polybutadiene $(150000 \mathrm{~g} / \mathrm{mol}$ vs $635000 \mathrm{~g} / \mathrm{mol})$. This means that if telechelic polymers are desired (at least functionality the closest to 2 as possible as it is not possible to have perfectly telechelic polymers with this method), one should start with precursors having the highest molar mass as possible.

Graphical representation of $M_{n}$ vs 1/Epoxy (\%) reveals again a linear relationship between the initial epoxidation rate and the final molar mass (Figure 7). Moreover, the linear regression of $M_{n N M R}$ and $M_{n}$ SEC showed a very reliable coefficient over 0.99 associated with a low value of intercept of the regression line (eq. 7 and 8, Figure 7). These results indicate that the controlled degradation of the EPB into ATPB is a better way to obtain well-defined polymer than the direct degradation by periodic acid allowing to obtain very small ATPB. The final mass of the ATPB can be chosen only by fixing the initial epoxidation rate.

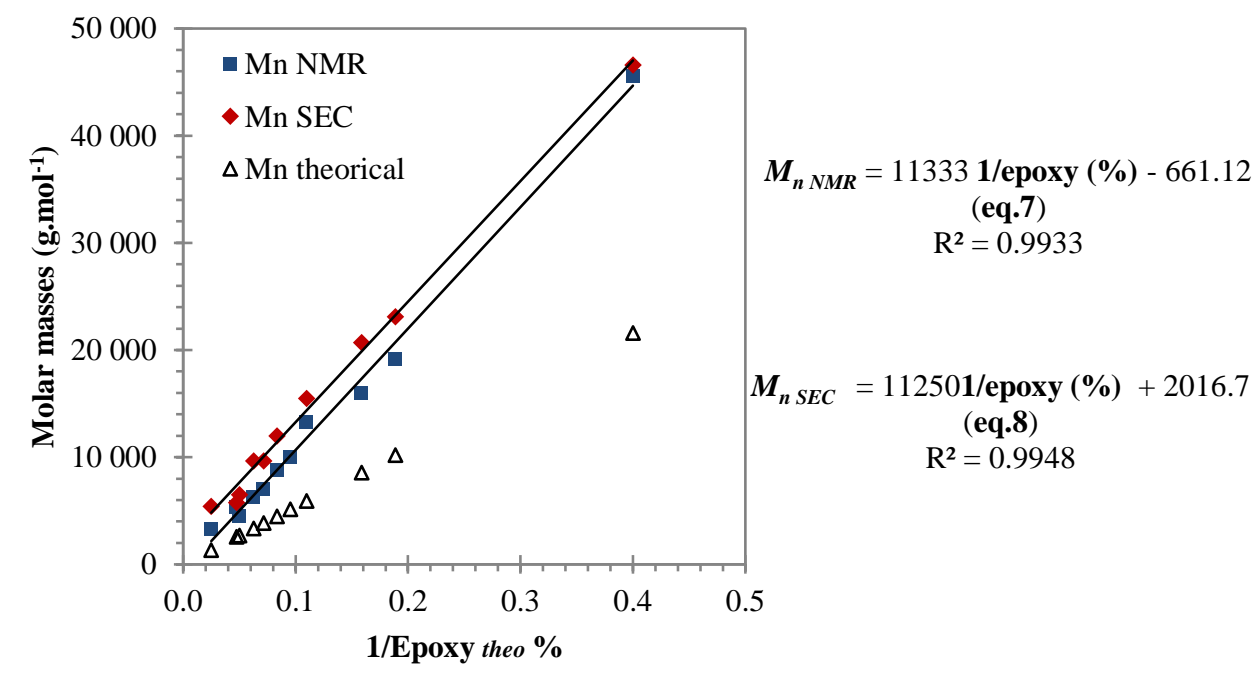

Figure 7: Evolution of $\mathrm{M}_{n}$ vs 1/Epoxy \% of the ATPB obtained by degradation of EPB with $\mathrm{H}_{5} \mathrm{IO}_{6}$.

\section{Conclusion}

In this study, two degradation methods of polydiene were used and compared in order to obtain small carbonyl telechelic PI and PB. For PB, the degradation in two steps (epoxidation and chain cleavage) is clearly better than the direct oxidative cleavage. Indeed, ATPB is obtained 
with a precise molar mass in a range 5000 to 50000 g. $\mathrm{mol}^{-1}$ with a relatively low dispersity $(1.4-1.8)$. It was also demonstrated for the first time that the degradation of the PB with periodic acid alone is not suitable for obtaining small ATPB. Therefore, the advantage of the method using the EPD must be qualified for the PI degradation. Indeed, both methods can be used to obtain small CTPI, but a slight advantage is given to the degradation of the EPI. The dispersity is lower and the control of the desired chain end is better. Concerning the functionality, if telechelic polymers are targeted, one has to start with a precursor of the highest possible molar mass in order to be very close to 2 . Finally, for the first time, the importance of the purification step to avoid the formation of acetal on the aldehyde chain end was also demonstrated.

\section{References}

1. Jerome, R.; Henrioulle-Granville, M.; Boutevin, B.; Robin, J. J. Telechelic polymers: Synthesis, characterization and applications. Prog. Polym. Sci. 1991, 16, 837-906.

2. Nikje, M. M. A.; Hajifatheali, H. Synthesis and characterization of terminally functionalized and epoxidized hydroxyl-terminated polybutadiene. Polym. Bull. 2012, 68, 973-982.

3. Krishnan, P. S. G.; Ayyaswamy, K.; Nayak, S. K. Hydroxy Terminated Polybutadiene: Chemical Modifications and Applications. J. Macromol. Sci. Part A 2013, 50, 128-138.

4. Dong, L.; Zhou, W.; Sui, X.; Wang, Z.; Cai, H.; Wu, P.; Zuo, J.; Liu, X. A CarboxylTerminated Polybutadiene Liquid Rubber Modified Epoxy Resin with Enhanced Toughness and Excellent Electrical Properties. J. Electron. Mater. 2016, 45, 3776-3785.

5. Lee, I.; Panthani, T. R.; Bates, F. S. Sustainable Poly(lactide-b-butadiene) Multiblock Copolymers with Enhanced Mechanical Properties. Macromolecules 2013, 46, 73877398. 
6. Morandi, G.; Kebir, N.; Campistron, I.; Gohier, F.; Laguerre, A.; Pilard, J.-F. Direct selective reductive amination of carbonyl telechelic oligoisoprenes: elaboration of promising tri- and tetrafunctionalized oligoisoprene intermediates. Tetrahedron Lett. 2007, 48, 7726-7730.

7. Kébir, N.; Campistron, I.; Laguerre, A.; Pilard, J.-F.; Bunel, C. New crosslinked polyurethane elastomers with various physical properties from natural rubber derivatives. J. Appl. Polym. Sci. 2011, 122, 1677-1687.

8. Berto, P.; Grelier, S.; Peruch, F. Telechelic Polybutadienes or Polyisoprenes Precursors for Recyclable Elastomeric Networks. Macromol. Rapid Commun. 2017, 38, 1700475.

9. Berto, P.; Pointet, A.; Le Coz, C.; Grelier, S.; Peruch, F. Recyclable Telechelic CrossLinked Polybutadiene Based on Reversible Diels-Alder Chemistry. Macromolecules 2018, 51, 651-659.

10. Nor, H. M.; Ebdon, J. R. Ozonolysis of natural rubber in chloroform solutionPart 1. A study by GPC and FTIR spectroscopy. Polymer 2000, 41, 2359-2365.

11. Rose, K.; Steinbüchel, A. Biodegradation of Natural Rubber and Related Compounds: Recent Insights into a Hardly Understood Catabolic Capability of Microorganisms. Appl. Environ. Microbiol. 2005, 71, 2803-2812.

12. Ravindran, T.; Nayar, M. R. G.; Francis, D. J. Production of hydroxyl-terminated liquid natural rubber-mechanism of photochemical depolymerization and hydroxylation. $J$. Appl. Polym. Sci. 1988, 35, 1227-1239.

13. Utara, S.; Moonart, U. Effects of Frequency and Sonication Time on Ultrasonic Degradation of Natural Rubber Latex. Adv. Mater. Res. 2013, 747, 721-724.

14. Solanky, S. S.; Campistron, I.; Laguerre, A.; Pilard, J.-F. Metathetic Selective Degradation of Polyisoprene: Low-Molecular-Weight Telechelic Oligomer Obtained from Both Synthetic and Natural Rubber. Macromol. Chem. Phys. 2005, 206, 1057-1063. 
15. Mouawia, A.; Nourry, A.; Gaumont, A.-C.; Pilard, J.-F.; Dez, I. Controlled Metathetic Depolymerization of Natural Rubber in Ionic Liquids: From Waste Tires to Telechelic Polyisoprene Oligomers. ACS Sustain. Chem. Eng. 2017, 5, 696-700.

16. Hillmyer, M. A.; Nguyen, S. T.; Grubbs, R. H. Utility of a Ruthenium Metathesis Catalyst for the Preparation of End-Functionalized Polybutadiene. Macromolecules 1997, 30, 718 721.

17. Gillier-Ritoit, S.; Reyx, D.; Campistron, I.; Laguerre, A.; Pal Singh, R. Telechelic cis-1,4oligoisoprenes through the selective oxidolysis of epoxidized monomer units and polyisoprenic monomer units in cis-1,4-polyisoprenes. J. Appl. Polym. Sci. 2003, 87, 4246.

18. Zhou, Q.; Jie, S.; Li, B.-G. Preparation of Hydroxyl-Terminated Polybutadiene with High Cis-1,4 Content. Ind. Eng. Chem. Res. 2014, 53, 17884-17893.

19. Zhou, Q.; Jie, S.; Li, B.-G. Facile synthesis of novel HTPBs and EHTPBs with high cis1,4 content and extremely low glass transition temperature. Polymer 2015, 67, 208-215.

20. Sadaka, F.; Campistron, I.; Laguerre, A.; Pilard, J.-F. Controlled chemical degradation of natural rubber using periodic acid: Application for recycling waste tyre rubber. Polym. Degrad. Stab. 2012, 97, 816-828.

21. Brosse, J. C.; Campistron, I.; Derouet, D.; El Hamdaoui, A.; Houdayer, S.; Reyx, D.; Ritoit-Gillier, S. Chemical modifications of polydiene elastomers: A survey and some recent results. J. Appl. Polym. Sci. 2000, 78, 1461-1477.

22. Fainleib, A.; Pires, R. V.; Lucas, E. F.; Soares, B. G. Degradation of non-vulcanized natural rubber - renewable resource for fine chemicals used in polymer synthesis. Polímeros 2013, 23, 441-450.

23. Orozco, J. S.; Cantow, H.-J. Guayule rubber centered block copolymers. Polym. Bull. 1984, 12, 203-208. 
24. Mauler, R. S.; Guaragna, F. M.; Gobbi, D. L.; Samios, D. Sonomechanical degradation of 1,4-cis-polyisoprene using periodic acid-solvent and temperature effect. Eur. Polym. J. 1997, 33, 399-402.

25. Reyx, D.; Campistron, I. Controlled degradation in tailor-made macromolecules elaboration. Controlled chain-cleavages of polydienes by oxidation and by metathesis. Angew. Makromol. Chem. 1997, 247, 197-211.

26. Kébir, N.; Campistron, I.; Laguerre, A.; Pilard, J.-F.; Bunel, C.; Couvercelle, J.-P.; Gondard, C. Use of hydroxytelechelic cis-1,4-polyisoprene (HTPI) in the synthesis of polyurethanes (PUs). Part 1. Influence of molecular weight and chemical modification of HTPI on the mechanical and thermal properties of PUs. Polymer 2005, 46, 6869-6877.

27. Li, H.; Loh, T.-P. Control of up to Five Stereocenters in a Cascade Reaction: Synthesis of Highly Functionalized Five-Membered Rings. J. Am. Chem. Soc. 2008, 130, 7194-7195. 